\title{
The Effects of Affect on Study Abroad Students
}

\section{Victor Savicki \\ Western Oregon University}

Being a study abroad student is not all sweetness and light. By definition, study abroad students are faced with acculturative stress (Berry, 2005) by virtue of encountering differences in assumptions, values, and expectations of daily living in their host culture. Add to that the usual challenge of hearing and speaking a different language, and the study abroad experience can jangle even the most robust of students.

On the plus side, the encounter with "differentness" can set the stage for a more open, ethnorelative (Bennett, 1993), and interculturally competent individual (Deardorff, 2008). As Bennett (2008) indicates as one of her five "Foundation Principles" for developing intercultural competence, "disequilibrium need not lead to dissatisfaction" (p. 17). In fact, "dynamic disequilibrium" (Joyce, 1984) may allow students to unfreeze their typical mindsets in order to encourage alternate points of view. However, a somewhat unexamined question concerns the consequences for students when disequilibrium edges over into discontent, distress or dejection. What are the effects of negative affective reactions to the study abroad situation? Well described phenomena such as culture shock (Ward, Bochner, \& Furnham, 2001), anxiety/uncertainty (Gudykunst, 1995), or inter-group contact anxiety (Frey \& Tropp, 2006) test students' coping abilities, especially when they are removed from habitual sources of emotional support and problem resolution. Overcoming hardships and culture clashes are the essence of students' exclamations that study abroad has changed their lives (Selby, 2008). But what are the consequences when these challenges provoke extended negative affect? This study attempts to describe possible outcomes. Prior to presenting a research study addressing these issues, a brief review of key concepts will be offered.

\section{Affect}

Affect is a general term subsuming various forms of emotion, feelings, and moods. It focuses on the emotional aspects of the human experience as distinct from the cognitive and behavioral sides. As humans we are hardwired for emotionality. Fear and anxiety that is inherent in the "fight or flight" 
sympathetic nervous system arousal is an evolutionary advantage for our species; as is the love and tenderness involved in caring for children and others in our family and social life. The quality of our emotional experiences is a significant determinant of our quality of life (Izard \& Ackerman, 1998).

Affect is inextricably linked to events in our environment. Early in development, some emotions arise fairly directly from neurological reactivity; for example, fear of falling, anger in reaction to frustration. As we develop cognitively and socially, other emotions appear that require thinking about standards and expectations (shame, guilt), or social comparison (envy, superiority) (Izard \& Ackerman, 1998). The cognitive mediational approach to stress and emotion (Lazarus, 1999) has played a major role in our understanding of how humans react to stressful events, and how they may be able to think their way to less problematic ways of feeling (Beck, 1967).

One point of view in the discipline of psychology promotes the idea that each type of emotion should be identified and understood separately. Anger, anxiety, sadness, joy, contentment, and excitement may all be seen as unique since they are likely to have different antecedents (Lazarus, 1999; Tuccitto, Giacobbi \& Leite, 2010). A contrasting view proposes that higher order affective categories may be created by aggregating emotions of similar tone (Zevon, \& Tellegen, 1982). Watson, Clark, and Tellegen (1988) argue that anxiety and fear, for example, are conceptually similar affective states because they both have a negative tone; therefore representing the same dimension of affect. For the purposes of simplicity, this study uses the latter conceptualization, that of aggregating emotions of a similar tone. Affect will be treated as either positively or negatively valenced (Watson, Clark, \& Tellegen, 1988).

\section{$A B C s$ of Acculturation}

Although affect is the emphasis of the current study, it cannot, in actuality, be separated from the totality of human responding. Ward (2001) offers a scheme to understand the integrated processes involved in acculturation that taps several levels of human experience. She describes three general categories in which study abroad sojourners in a foreign culture may react: the ABCs of acculturation. The first, Affect (A), is most related to stress, coping, and psychological well-being. Using the theoretical model of Lazarus and his colleagues, researchers can examine the person-environment interaction inherent in stress and coping (Lazarus \& Folkman, 1984; Lazarus \& Smith, 1988). Key to this approach to stress and coping is cognitive appraisal of both the stressor in the environment and the individual's resources to cope with the stressor. In the face of an identical stressor different individuals may react differently depending on how they appraise it. Some may see the stressor, 
coupled with their adequate coping resources, as a challenge that mobilizes them to higher levels of performance and resulting higher levels of selfsatisfaction and self-esteem. Others might see the stressor, coupled with their possibly inadequate coping resources as a threat which may overwhelm them thus evoking anxiety and fear. Still others might see the stressor coupled with depleted coping resources as producing harm and loss with subsequent feelings of depression and grief. From this theoretical point of view, clearly the manner in which one thinks about an environmental event has affective consequences.

The Positive Psychology movement (Seligman, 2002) encourages researchers to incorporate positive expressions of psychological well-being as a balance to focusing solely on psychopathology. Study abroad students may suffer psychological distress in the form of anxiety, depression, hostility, and somatic disorders. They also may experience enhanced well-being and satisfaction with life (Diener, Emmons, Larsen, \& Griffin, 1985). These two expressions of psychological well-being, though somewhat inversely related, seem to tap somewhat different expressions of well-being or its absence. From the point of view of international educators, lower symptoms and higher satisfaction may seem like a self-evident goal (Savicki, 2010). Yet, the linkage of expressions of well-being to other categories of study abroad outcomes needs further empirical examination (Savicki, 2012)

Behavior (B), as the second component of the ABCs of behavior, focuses primarily on those overt actions and skills that may indicate that a study abroad student is "fitting in" with the host culture (Ward \& Kennedy, 1999). Ward (2001) suggests that behavioral adaptation to a new culture follows a social learning approach in which sojourners, such as study abroad students, are faced with learning new skills and behaviors to ease their ability to interact. Such learning may require not only developing a culture relevant behavioral repertoire, but also suppressing more habitual, home culture responses. The cultural learning curve is quite steep initially, but seems to level off after about six months in the host culture (Ward \& Kennedy, 1999). In addition to measuring the difficulty of performing culturally appropriate behaviors in various circumstances, it may also be relevant to determine how much of a study abroad student's time is spent in direct contact with host culture nationals, and how much the student uses the host culture language in various intercultural situations (Engle \& Engle, 2003). Such measures may be an indication of how immersed the student may be in the host culture, and thus how much opportunity the student may have to adapt successfully.

Finally, Cognition (C), the third component of the ABCs focuses specifically on a study abroad student's social identification (Ward, 2001). The emphasis here is on the mental schema the student has regarding his 
or her national identity, and how that identity may be compared with the assumptions and values of the host culture. Many students, prior to studying abroad, have not had the opportunity to stand aside from the home culture in which they are ensconced. Many students, in response to this first headto-head comparison of cultures find that they can now articulate aspects of their home culture that had been assumed without examination, and that they come to appreciate their home culture more intensely as a result (Savicki \& Cooley, 2011). Indeed, they may espouse a national identity higher than that of students who did not experience a study abroad sojourn (Savicki, Cooley, \& Donnelly, 2008). Given that most university students studying abroad fall into the late adolescent age category, such identity exposure and exploration coincides with their developmental task of establishing and solidifying a selfidentity (Marcia, 1980).

In summary, the $\mathrm{ABC}$ of acculturation form a framework for examining the outcomes of study abroad, from a psychological perspective. Although some research exists that examines the linkages in the acculturation context generally (Ward, Bochner, \& Furnham , 2001), more specificity is required focusing on the study abroad experience as a unique context. The current study attempts to provide such specificity.

\section{Hypotheses}

The general prediction of this study is that lower affect (lower positive affect and higher negative affect) will negatively impact various ABC of acculturation indicators.

Hypothesis 1. Students with lower positive and higher negative affect will experience more difficulties during their study abroad sojourn in other affective responses: stress appraisal, psychological symptoms, and life satisfaction

Hypothesis 2. Students with lower positive and higher negative affect will experience more difficulties during their study abroad sojourn with intercultural behavioral responses: socio-cultural adaptation, contact with host nationals, host cultural language use.

Hypothesis 3. Students with lower positive and higher negative affect will experience more difficulties during their study abroad sojourn with cognitive responses: commitment to their American identity and exploration of their American identity. 


\section{Methods}

\section{Participants}

Participants were thirty two U.S. university students studying abroad for three months in Argentina. The average age was 21.3, 45\% were male, $10 \%$ were Sophomores, $50 \%$ Juniors, and $40 \%$ Seniors. Some fluency in Spanish language was required for admission to the program. On average they had completed 2.5 years of high school Spanish and 1.3 years of university Spanish, though there was a wide range of previous language study. All students participated in four hours per week of both Spanish grammar, and Spanish conversation courses during their sojourn. Academic coursework in both English and Spanish was available during the sojourn.

\section{Measures}

Positive and Negative Affectivity Schedule (PANAS). Positive and negative mood were assessed with the PANAS; (Watson, Clark, \& Tellegen, 1988). The Positive Activation (PA)subscale lists ten adjectives related to positive mood (e.g. active, alert, attentive). The Negative Activation (NA) subscale lists ten adjectives related to negative mood (e.g. afraid, ashamed, distressed). Participants were asked to rate the extent to which they had felt each of these emotions over the previous three months. Ratings were made on a five point Likert scale, ranging from $1=$ Very slightly or not at all to $5=$ Extremely. Alphas for the current sample were Positive Activation, .852; Negative Activation, .823 .

The Appraisal of Life Events (ALE) scale. The ALE (Ferguson, Matthews, \& Cox, 1999) assesses cognitive appraisal of stressful situations via three dimensions: Challenge (six items), the degree to which the environment is perceived as one that allows for personal growth and development through potential mastery of stressors; Threat (six items), the degree to which the environment is perceived as hostile, apt to generate anxiety, and may be potentially harmful; and Loss (four items), the potential for suffering and sadness. Participants were asked to appraise "my study abroad experience" on sixteen adjectives (e.g. stimulating, exciting, fearful, hostile, depressing, painful) using a five point Likert scale ranging from $1=$ Not at all, to $5=$ Very much so. Alphas for the current sample were Challenge, .861; Threat, .817, and Loss, .895 .

Socio-cultural Adaptation Scale (SCAS). In the SCAS Ward and Kennedy (1999) have identified a list of encounters, and issues that may be relevant to sociocultural adjustment. Respondents rate their difficulty in adjusting to cultural situations using a five point Likert scale with $1=$ No difficulty to 5 
= Extreme difficulty. A brief sample of their twenty nine item scale includes "Making friends," "Using the transport system," "Going shopping," "Dealing with unsatisfactory service," "Getting used to the local food/finding food you enjoy," "Dealing with people in authority," "Understanding the locals' world view" (Ward \& Kennedy, 1999 p. 663). Reliability based on Cronbach's alpha for the current sample was .83 .

American Identity Measure (AIM). The AIM (Meyer-Lee \& Evans, 2008) is a social identification scale developed to assess study abroad students' sense of self in terms of their feelings of belonging to and attitudes toward the larger U.S. society. This ten item scale derives from the work of Phinney and colleagues (Phinney, 1992; Phinney \& Devish-Navarro, 1997). Students responded on a four point Likert scale from $1=$ Strongly Disagree to $4=$ Strongly Agree. Two factor analyzed sub-scales assessed the two components of American Identity. Factor 1 (five items), Commitment/Affirmation (CA), assessed the attachment and personal investment to being an American with items such as "I have a strong sense of being an American," and "Being an American plays an important part in my life." Factor 2 (five items), Exploration/Search (ES), assessed the process of seeking information and experiences relevant to defining one's own "American-ness" with items such as "I have spent time trying to find out more about what being American means," and "I have sometimes wondered about the meaning or implications of being American." Alphas for the current sample were $\mathrm{CA}=.805, \mathrm{ES}=.819$.

Brief Symptom Inventory (BSI). Psychological well-being/strain was measured based on four sub-scales from the BSI (Derogatis \& Melisaratos, 1983). The five to six item symptom cluster scales included were Somatization: distress arising from perceptions of bodily dysfunction; Depression: dysphoria and lack of motivation and energy; Anxiety: nervousness, panic attacks, apprehension, dread; and Hostility: thoughts, feelings or actions of anger. Coefficient alphas for the sub-scales were Somatization .800, Depression .885, Anxiety .781, Hostility .523.

Satisfaction with Life Scale (SWLS). The SWLS is a five item questionnaire using a seven point Likert scale to rate overall satisfaction with life using questions such as "In most ways my life is close to my ideal" (Diener, Emmons, Larsen, \& Griffin, 1985). The SWLS can be viewed as a measure of psychological adjustment since the scale demonstrated moderately strong criterion validity with several measures of psychological well-being (Diener, Emmons, Larsen, \& Griffin, 1985 pp. 72-73). Alpha for the current sample was .879.

Personality. Personality was measured using a short version of the Big Five personality factor approach (Fossum, Weyant, Etter, \& Feldman-Barrett, 
1996). For this thirty five item scale, each sub-scale had seven items. The scales and key defining traits for each include: 1) Neuroticism: anxious, hostile, selfconscious; 2) Extraversion: outgoing, sociable, upbeat, assertive; 3) Openness to experience: curiosity, flexibility, unconventional attitudes; 4) Agreeableness: sympathetic, trusting, cooperative, straightforward; 5) Conscientiousness: diligent, disciplined, well-organized, dependable. Alphas for the sub-scales in this sample are Neuroticism .783, Extraversion .793, Openness .766, Agreeableness .571, Conscientiousness . 707.

Intercultural Adjustment Potential Scale (ICAPS). The ICAPS consists of fifty five items with responses given on a scale ranging from $1=$ Strongly Disagree to 7 = Strongly Agree. A total score (ICAPS Total) was computed by summing all items (twenty four reverse coded) with higher scores indicating greater adjustment potential (Matsumoto, et al., 2001). This scale has demonstrated predictive validity for adjustment to a new culture based on peer and expert interviewer ratings, as well as self and subjective ratings (Matsumoto, et al., 2001 p 492). Four factor scores were also derived - Emotion Regulation (ER): the ability to modulate one's emotional reactions to avoid employing psychological defenses, Openness (OP): the ability to engage in learning about the new culture, Flexibility (FL): being free of over-attachment to previous ways of thinking and willingness to tolerate ambiguity, and Critical Thinking (CT): the ability to generate creative, new hypotheses about incidents in the new culture that go beyond one's home cultural framework. All five ICAPS scores were transformed to T-scores with a mean of fifty and standard deviation of ten based on a normative sample. The authors of the scale reported alphas of .783 for the ICAPS Total, .638 for Emotional Regulation, .601 for Openness, .568 for Flexibility, .433 for Critical Thinking (Matsumoto, et al., 2001).

General Contact levels. Percent of contact with individuals from different cultures was measured by student responses to the following question given at the end of the study abroad term:

When thinking about the last month, please estimate the percent of time you spent in face to face contact with the following kinds of people (the percentages should add to $100 \%$ ). In situations in which you may encounter more than one type of person at once (e.g. host culture teacher in a class with fellow American students), please count that as contact with the host culture.

The response alternatives were 1. American students, 2. People in the host culture (teachers, shop keepers, other students, etc), and 3. People of a different culture (neither home nor host culture).

Entry Spanish language fluency. Upon arriving in Argentina, students took a locally constructed Spanish language placement test, and were assigned to 
five different levels based on their test performance. Each student's assigned level (one to five) represents their entry language fluency.

Spanish language usage. At the end of the term students responded to a six item language usage questionnaire that employed a constant sum procedure following Laroche, Pons, and Richard (2009). Students estimated the percentage of Spanish and English they used in specific situations; e.g. "read newspapers and magazines," "listen to radio or watch TV," "go travelling," "go shopping." In these situations, use of the host culture language was "discretionary" in the sense that no rules of behavior dictated that a particular language be used as was the case in classroom activities, or while communicating with non-English speaking host families. Cronbach's alpha was .805.

\section{Procedures}

Students voluntarily responded to a pre-departure questionnaire immediately prior to or upon arrival at their study abroad program. They completed the post program questionnaire during week eleven of the twelve week program. All data was treated with confidentiality. In order to facilitate the examination of the effects of affect in this study, an index of affect was computed using the Positive Activation and Negative Activation scales of the PANAS. Theses scales are statistically independent of one another $(r=-.17, p=$ ns) so their combination took advantage of both scale perspectives. The Mood Index was calculated as follows: Positive Activation minus Negative Activation. Higher scores thus indicate both higher Positive and lower Negative affect; conversely lower scores indicate both lower Positive and higher Negative affect. The sample was then split at the median to produce a Higher Mood group $(n=17)$ and a Lower Mood group $(n=15)$. The Higher Mood group may be characterized as experiencing more positive and fewer negative feelings during their study abroad; the Lower Mood group may be characterized as experiencing fewer positive and more negative feelings during the same period. This grouping strategy aimed to discriminate between the different affective experiences of students and to facilitate finding distinctions in outcomes associated with the different experiences.

\section{Results}

At the outset, it will be useful to put the study abroad students' affectivity levels in perspective. Figure 1 illustrates the relationship of the two Mood groups to each other and to a norm group of college students assembled as part of the original development of the PANAS (Watson, Clark, \& Tellegen, 1988). Several patterns emerged. First, as is generally the case, PA was stronger than NA for all groups. Second, the distinctions on PA and NA for the two Mood 
groups show clearly. The scores for these groups were significantly different for both scales (NA, $t=3.846, \mathrm{p}<.001$; PA, $t=-5.363 \mathrm{p}<.001$ ). The profiles of the Mood groups in relation to the normative group indicate that the Lower Mood group looks very consistent with the norm; while the Higher Mood group shows quite elevated PA and depressed NA. In sum, it is the Higher Mood group that is most deviant from the norm, with higher PA and lower NA. The Lower Mood group looks much like the U.S. college student norm. Therefore, the Lower Mood group's disequilibrium in affect, on average, seems not to cross the line into the problematic range. Nevertheless, their lowered affect level was associated with significant concerns for study abroad educators and administrators.

Figure 1. Comparison of High and Low Mood groups with PANAS college student norm group

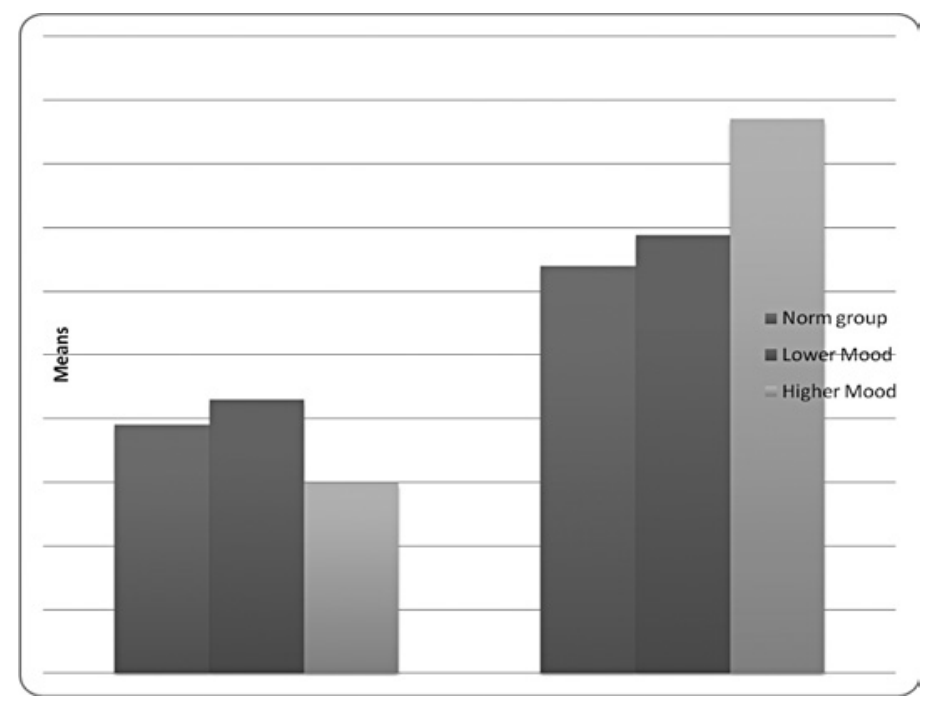

The Mood groups were not different on the level of student language proficiency assessed at the beginning of the academic semester $(F=.289$, $p=$ $\mathrm{ns})$, nor on their anticipated difficulty in adaptation to the Argentine culture $(F=.066, p=n s)$. On these variables the groups started even. But, as Table 1 indicates, a pattern of differences occurred by the end of the semester on all of the $\mathrm{ABC}$ categories. 
Table 1. Univariate F tests for Affect Index groups with study abroad outcome variables.

\begin{tabular}{|c|c|c|c|c|}
\hline & & \multicolumn{2}{|l|}{ Mood groups } & \multirow[b]{2}{*}{$F$} \\
\hline & & Lower Mood & $\begin{array}{l}\text { Higher } \\
\text { Mood }\end{array}$ & \\
\hline \multicolumn{5}{|l|}{ Affective Variables } \\
\hline \multicolumn{5}{|l|}{ Stress Appraisal } \\
\hline \multirow[t]{2}{*}{ Challenge } & Mean & 3.833 & 4.480 & $6.069^{*}$ \\
\hline & Std. Error & 0.191 & 0.180 & \\
\hline \multirow[t]{2}{*}{ Threat } & Mean & 1.344 & 0.716 & $9.387^{* *}$ \\
\hline & Std. Error & 0.150 & 0.141 & \\
\hline \multirow[t]{2}{*}{ Loss } & Mean & 1.083 & 0.294 & $6.970^{\star \star}$ \\
\hline & Std. Error & 0.218 & 0.205 & \\
\hline \multicolumn{5}{|c|}{ Psychological Symptoms } \\
\hline \multirow[t]{2}{*}{ Anxiety } & Mean & 0.644 & 0.265 & $4.928^{*}$ \\
\hline & Std. Error & 0.125 & 0.117 & \\
\hline \multirow[t]{2}{*}{ Hostility } & Mean & 0.720 & 0.341 & $6.541^{*}$ \\
\hline & Std. Error & 0.108 & 0.101 & \\
\hline \multirow[t]{2}{*}{ Somaticism } & Mean & 0.495 & 0.261 & 1.507 \\
\hline & Std. Error & 0.139 & 0.131 & \\
\hline \multirow[t]{2}{*}{ Depression } & Mean & 0.844 & 0.216 & $9.599^{\star \star}$ \\
\hline & Std. Error & 0.148 & 0.139 & \\
\hline \multicolumn{5}{|l|}{ Satisfaction } \\
\hline \multirow[t]{2}{*}{ SWLS } & Mean & 25.067 & 31.706 & $13.857^{* * *}$ \\
\hline & Std. Error & 1.300 & 1.221 & \\
\hline \multicolumn{5}{|l|}{ Behavioral Variables } \\
\hline \multirow[t]{2}{*}{ Language usage } & Mean & 47.333 & 78.433 & $6.063^{*}$ \\
\hline & Std. Error & 6.756 & 6.756 & \\
\hline \multicolumn{5}{|l|}{ Cultural Adaptation } \\
\hline \multirow[t]{2}{*}{ SCAS } & Mean & 1.906 & 1.670 & $5.752^{*}$ \\
\hline & Std. Error & 0.073 & 0.066 & \\
\hline \multicolumn{5}{|l|}{ Percent contact } \\
\hline \multirow[t]{2}{*}{ Peer cohort } & Mean & 56.000 & 47.706 & 2.159 \\
\hline & Std. Error & 4.181 & 3.794 & \\
\hline \multirow[t]{2}{*}{ Host culture } & Mean & 35.571 & 38.529 & 0.285 \\
\hline & Std. Error & 4.104 & 3.725 & \\
\hline \multirow[t]{2}{*}{ Other culture } & Mean & 7.714 & 13.647 & 1.638 \\
\hline & Std. Error & 3.433 & 3.115 & \\
\hline \multicolumn{5}{|l|}{ Cognitive Variables } \\
\hline \multirow[t]{2}{*}{ AIM Commit/Affirm } & Mean & 3.027 & 3.424 & $3.997^{*}$ \\
\hline & Std. Error & 0.145 & 0.136 & \\
\hline \multirow[t]{2}{*}{ AIM Explore/Search } & Mean & 2.533 & 2.765 & 1.046 \\
\hline & Std. Error & 0.165 & 0.155 & \\
\hline
\end{tabular}

${ }^{*} p<.05,{ }^{*} p<.01,{ }^{*} p<.001$ 


\section{Differences in affect (A)}

As Ward and her colleagues suggest (Ward, 2001; Ward, Bochner, \& Furnham , 2001) the A, affective, realm of the ABCs of acculturation is related to stress and well-being. With regard to stress, measures of stress appraisal (Lazarus, 1999) indicated that the Lower Mood group viewed their study abroad experience as significantly less challenging, but significantly more threatening, and with higher loss. This combination of stress appraisals indicates that the Lower Mood group saw their experience as less amenable to mastery, more anxiety provoking, and more psychologically harmful. The reverse was true for the Higher Mood group.

With regard to well-being, two perspectives on psychological well-being show a similar result while probing for differing expressions of it. The Lower Mood group was significantly higher in a number of scales that indicate concerns about psychological symptoms: Anxiety, Hostility, and Depression. Their study abroad experience was tainted with degrees of such psychological distress, while the Higher Mood group showed few such concerns. Taken from a different point of view, Lower Mood groups showed significantly lower overall satisfaction with life than did the Higher Mood group. The Lower Mood group members may have edged beyond simple disequilibrium into a level of affective response that was more worrisome.

To some extent, it is not surprising that student groups sorted by mood might show differences in other affective measures such as stress appraisal, psychological symptoms, and life satisfaction. However, affectivity had effects beyond stress and well-being.

\section{Differences in behavior (B)}

The behavioral (B) realm of the ABCs of acculturation focuses on actions that may indicate that students have acquired skills, or are participating in activities that help them partake of the day-to-day stream of life in the host culture. The first of these indicators was the percentage of the host culture language students actually used in specific, discretionary situations in which they might choose to use Spanish over English, or to generally avoid using their host culture language entirely. The Lower Mood group used Spanish significantly less in these situations than did the Higher Mood group. The mean difference was approximately thirty percentage points. The Lower Mood group seemingly showed some reluctance, and possibly engaged in some avoidance in using the host culture language beyond that required in their classes.

The second indicator of acquisition of behavioral skills was the level of difficulty students felt in common types of actions that might be demanded of 
them in the course of host culture daily living, as operationalized by the Sociocultural Adaptation Scale. The Lower Mood group showed significantly higher overall difficulty than did the Higher Mood group. The Lower Mood group showed a significant decrease in difficulty from pre-departure anticipation of difficulty to final reports of difficulty $(\mathrm{t}=3.772, \mathrm{p}<.01)$; however, they did not reduce reports of difficulty as much as did the Higher Mood group.

The third indicator of behavioral participation in the host culture was the percent of time students allotted to interaction with various groups during their sojourn. In this case, there were no significant differences between the Lower and Higher Mood groups in the percentage time spent with their Peer Cohort from the U.S., people from the Host Culture, or people from Other Cultures. The Lower Mood group did spend a bit more time with their U.S. peers, and a bit less time with host culture natives, but the differences were not statistically significant. Thus, on this behavioral indicator, affectivity seemed not to be implicated.

\section{Differences in cognition (C)}

The final component of the ABCs of acculturation is cognition (C). By this Ward (2001) refers to the level of social identification expressed by the students. In this study, such identification was operationalized by the AIM, which captured two aspects of American identity (Meyer-Lee \& Evans, 2008). Lower Mood groups showed significantly less Commitment and Affirmation of their American identity than did the Higher Mood group. That is, they did not use the opportunity of comparing their own culture with the Argentine culture to arrive at a greater appreciation of their home culture. The Lower Mood group stayed approximately at the same level of Commitment and Affirmation throughout their sojourn, while the Higher Mood group increased their Commitment and Affirmation to a marginally significant degree $(t=-2.023$, $p<.10)$. The groups were not different on the Exploration-Search factor.

In summary, the level of affectivity reported by the two groups was related to differences in all three aspects of acculturation as described by the ABC model. None of these results reflects serious personal psychological issues, but rather more subtle, yet potent responses that may frame some students' study abroad experience. Taken as a whole, these differences portray a substantially different study abroad experience for members of the two groups.

\section{Discussion and Conclusions}

There appears to be no homogeneous study abroad experience (Savicki, 2010). The two groups in this study reported significantly different psychological adjustment, behavioral performance, and social identification 
outcomes even though they were in the same program at the same time. The Lower Mood group put themselves in similar situations with regard to contact with both their U.S. peers and with host nationals as did the Higher Mood group; yet they reacted differently. Study abroad educators may wish that all students show the higher positive and lower negative affect illustrated by the Higher Mood group. However, the difficulties experienced by the Lower Mood group cannot be ignored; especially when they seem to be related to poorer outcomes in terms of socio-cultural adaptation, language use, and national identity evaluation. For the Higher Mood group disequilibrium did not lead to dissatisfaction; for the Lower Mood group it did. One consolation was that the level of psychological distress of the Lower Mood group did not, on average, edge into the range requiring professional care.

Typical predictors of study abroad outcome did not reveal potential affective reactions. No differences existed between groups on level of language proficiency or on years of language studied in high school or university; no differences existed in number of friends from other cultures, weeks of travel to foreign countries, or previous foreign exchange experiences. By looking at the typical information collected on applications, one could not determine the level of risk for issues of affectivity during study abroad.

However, predictors at the psychological level foreshadowed affective reactions to some extent. Student mood reported at the end of the sojourn was significantly related to pre-departure levels of Emotional Regulation $(r=.508$, $p<.05)$, Extraversion $(r=.549, p<.05)$, and Satisfaction with Life $(r=.486$, $p<.05)$. Students who were already psychologically adjusted, outgoing, and emotionally flexible adapted better to the stresses of uncertainty and changes in their physical and social environment (Zautra, Potter, \& Reich, 1998). Such students were better able to cope with whatever disequilibrium their sojourn exposed them to.

Although study abroad educators can hope that their students embody the characteristics just mentioned, it is clear that there is a range of psychological readiness to face study abroad uncertainties. With the increase in students applying to study abroad (Commission on the Abraham Lincoln Study Abroad Fellowship Program, 2005), that range is likely to widen. Additionally, university students generally seem to be experiencing more concerns about their mental health (Adlaf, Gliksman, Demers, \& Newton-Taylor, 2001; Lewin, 2001). Thus, it is likely that more students who are psychologically vulnerable will apply for study abroad. More students will experience lower mood states. More students will have less than ideal outcomes on a variety of study abroad measures. The field needs to prepare itself to address these concerns. 
The education abroad field has often focused on the benefits of immersion as the sine qua non of study abroad (Engle \& Engle, 2003); yet study abroad might be better seen as a more expanded experience encompassing predeparture activities and assessment, on-site support, along with re-entry and follow-up framing of sojourn experiences (Hoff \& Paige, 2008). Pre-departure efforts might help to bolster psychological skills necessary for coping with a foreign culture. On-site support might focus not only on early skill building and culture-specific knowledge, but also on repeated, sojourn-long miniassessments of mood, with appropriate intervention as necessary. Finally, reentry and follow-up might help students reframe their experiences and mood states in a way that builds on transferable skills and knowledge to be applied in students' home culture; after the fact re-appraisal might celebrate survival and efficacy in difficult situations. In any event, lower affective responses to study abroad should not be ignored as acceptable or inevitable.

\section{Author Note}

Special thanks to Site Director María Nélida de Juano, teachers and staff at the Programa Internacional Facultdad de Derecho, Universidad Nacional de Rosario. Particularly thanks to the Spanish Conversation class teachers Sabina Chiaverano, Gabriele Alcañiz, Soledad Aramburu, Gisel Panza, Karina llopart who allowed me to collect data in their classes; and special recognition to María Fernanda González for her good efforts at collecting the end of the term questionnaires.

\section{References}

Adlaf, E. M., Gliksman, L., Demers, A., \& Newton-Taylor, B. (2001).

The prevalence of elevated psychological distress among Canadian undergraduates: Findings from the 1998 Canadian campus survey. Journal of American College Health, 50, 67-72.

Beck, A. T. (1967). Depression: Clinical, Experimental and Theoretical Aspects. New York: Harper and Row.

Bennett, J. M. (2008). On becoming a global soul: A path to engagement on study abroad. In V. Savicki, (Ed). Developing Intercultural Competence and Transformation: Theory, Research, and Application in International Education. Sterling, VA: Stylus Publishing.

Bennett, M. J. (1993). Towards ethnorelativism: A developmental model of intercultural sensitivity. In M. Paige (Ed.), Education for the intercultural experience (21-71). Yarmouth, ME: Intercultural Press. Inc.

Berry, J. W. (2005). Acculturation. In W. Friedlmeier, P. Chakkarath, \& B. 
Schwarz (Eds.) Culture and Human Development (pp. 291-302). New York, NY: Psychology Press.

Commission on the Abraham Lincoln Study Abroad Fellowship Program (2005). Global competence and national needs: One million Americans studying abroad. Retrieved January 25, 2011 from http://www. culturalinsurance.com/pdf/lincoln_final_report.pdf.

Deardorff, D. K. (2008). Intercultural competence: A definition, model, and implications for education abroad. In V. Savicki, (Ed). Developing Intercultural Competence and Transformation: Theory, Research, and Application in International Education (pp. 32-51). Sterling, VA: Stylus Publishing.

Derogatis, L. R. \& Melisaratos, N. (1983). The brief symptom inventory: An introductory report. Psychological Medicine, 13, 595-605.

Diener, E., Emmons, R. A., Larsen, R. J., \& Griffin, S. (1985). The satisfaction with life scale. Journal of Personality Assessment, 49, 71-75. Engle, L. \& Engle, J. (2003). Study abroad levels: Toward a classification of program types. Frontiers: The Interdisciplinary Journal of Study Abroad, IX, 1-20.

Ferguson, E. Matthews, G. \& Cox, T. (1999). The appraisal of life events (ALE) scale: Reliability and validity. British Journal of Health Psychology. 4, 97-116.

Fossum, T.A., Weyant, S.A., Etter, L., Feldman Barrett, L. (1998, May). A short and simple alternative to long personality questionnaires. Presented at the annual meeting of the American Psychological Society, Washington, DC.

Frey, F. E. \& Tropp, L. R. (2006). Being seen as individuals versus as group members: Extending research on metaperception to intergroup contexts. Personality and Social Psychology Review, 10, 265-280.

Gudykunst, W. B. (1995). Anxiety/uncertainty management (AUM) theory. In R. L. Wiseman (Ed.), Intercultural communication theory (pp. 8-58). Thousand Oaks CA: Sage.

Hoff, J. G. \& Paige, R. M. (2008). A strategies-based approach to culture and language learning in education abroad programming. Frontiers: The Interdisciplinary Journal of Study Abroad, XVII, 89-105.

Izard, C. E. \& Ackerman, B. P. (1998). Emotion and self-concepts across the life span. Annual Review of Gerontology and Geriatrics, 17, 1-6.

Joyce, B. R. (1984). Dynamic disequilibrium: The intelligence of growth. Theory into Practice, 23. 26-34.

Laroche, M., Pons, F., \& Richard, M. (2009). The role of language in ethnic 
identity measurement: A multitrait-multimethod approach to construct validation. The Journal of Social Psychology, 149, 513-539.

Lazarus, R. S. (1999). Stress and emotion: A new synthesis. NY: Springer Publishing.

Lazarus, R. S., \& Folkman, S. (1984). Stress, appraisal, and coping. New York: Springer.

Lazarus, R. S. \& Smith, C. (1988). Knowledge and appraisal in the cognition-emotion relationships. Cognition and Emotion, 2, 281-300.

Lewin, T. (2011). Record level of stress found in college freshmen. New York Times [Electronic version]. Retrieved January 27, 2011 from http:// www.nytimes.com/2011/01/27/education/27colleges.html?_r=1\&hp Marcia, J. (1980). Identity in adolescence. In J. Addison (ed.). Handbook of adolescent psychology (pp. 159-187). NY: Wiley.

Matsumoto, D., LeRoux, J. A., Iwamoto, M., Choi, J. W., Rogers, D., Tatani, H., \& Uchida, H. (2003). The robustness of the Intercultural Adjustment Potential Scale (ICAPS): The search for a universal psychological engine of adjustment. International Journal of Intercultural Relations, 27, 543-56.

Meyer-Lee, E. \& Evans, J. (2008, May). New tools for intercultural outcomes learning assessment In D. Deardorff (Chair) Assessment toolbox for international educators. Symposium presented at the NAFSA Annual Conference, Washington, DC.

Phinney, J. S. (1992). The Multigroup Ethnic Identity Measure: A new scale for use with adolescents and young adults from diverse groups. Journal of Adolescent Research, 7, 156-176.

Phinney, J. S. \& Devich-Navarro, M. (1997). Variations in bicultural identification among African American and Mexican American adolescents. Journal of Research on Adolescence, 7, 3-32.

Savicki, V. (2010). Implications of early sociocultural adaptation for study abroad students. Frontiers: The Interdisciplinary Journal of Study Abroad XIX, 205-223.

Savicki, V. (2012). The psychology of student learning abroad. In M. Vande Berg, R. M. Paige, \& K. H. Lou, Education Abroad for the Learner: Theory, Research, Design, \& Training, (pp.215-238)Sterling, VA: Stylus Publishing.

Savicki, V. \& Cooley, E. (2011) American identity in study abroad students: Contrasts and changes. Journal of College Student Development. 52, 339349.

Savicki, V., Cooley, E., \& Donnelly, R. (2008). Acculturative stress, appraisal, coping and intercultural adjustment. In V. Savicki, (Ed.). Developing 
Intercultural Competence and Transformation: Theory, Research, and Application in International Education (pp. 173-192). Sterling, VA: Stylus Publishing.

Selby, R. (2008). Designing transformation in international education.

In V. Savicki, (Ed). Developing Intercultural Competence and

Transformation: Theory, Research, and Application in International Education (pp. 1-10). Sterling, VA: Stylus Publishing.

Seligman, M. E. P. (2002). Positive psychology, positive prevention, and positive therapy. In C. R. Snyder \& S. J. Lopez. Handbook of Positive Psychology, pp 3-12. New York: Oxford University Press.

Tuccitto, D. E., Giacobbi, P. R., \& Leite, W. L. (2010). The internal structure of positive and negative affect: A confirmatory factor analysis of the PANAS. Educational and Psychological Measurement, 70, 125141.

Ward, C. (2001). The A, B, Cs of acculturation. In D. Matsumoto (Ed.), Handbook of Culture and Psychology. (pp. 411-446). NY: Oxford University Press.

Ward, C., Bochner, S., \& Furnham, A. (2001). The Psychology of Culture Shock $2^{\text {nd }}$ Ed. London: Routledge.

Ward, C. \& Kennedy, A. (1999). The measurement of sociocultural adaptation. International Journal of Intercultural Relations 23. 659-677.

Watson, D, Clark L.A., Tellegen, A, (1988). Development and validation of brief measures of positive and negative affect: The PANAS scales. Journal of Personality and Social Psychology, 54, 1063-1070.

Zautra, A. J., Potter, P. T., \& Reich, J. W. (1998). The independence of affects is context-dependent: An integrative model of the relationship between positive and negative affect. Annual Review of Gerontology and Geriatrics, 17, 75-103.

Zevon, M. A., \& Tellegen, A. (1982). The structure of mood change: An idiographic/nomothetic analysis. Journal of Personality and Social Psychology, 43, 111-122. 